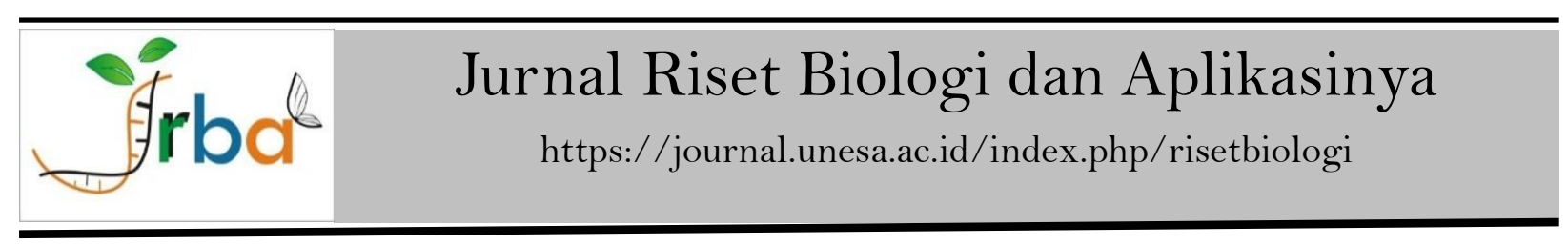

\title{
Jenis-jenis Gulma Pada Kebun Tebu di Kecamatan Asembagus, Situbondo, Jawa Timur: Kelompok Eudikotiledon
}

\section{Weeds of Sugar Cane Fields in Asembagus Sub-District, Situbondo, East Java: Eudicots}

\section{Muhammad Rifqi Hariri ${ }^{1 *}$, Arifin Surya Dwipa Irsyam²}

${ }^{1}$ Pusat Penelitian Konservasi Tumbuhan dan Kebun Raya, Lembaga Ilmu Pengetahuan Indonesia ${ }^{2}$ Herbarium Bandungense (FIPIA), Sekolah Ilmu dan Teknologi Hayati (SITH),

\author{
Institut Teknologi Bandung
}

\section{History Article}

Received : 15 Juni 2019

Approved : 10 Juli 2019

Published : 30 September 2019

Keywords:

Eudicots, Situbondo, sugar cane, weeds

Kata Kunci: Eudikotiledon, gulma, Situbondo, tebu

\begin{abstract}
Abstrak
Agroekosistem perkebunan tebu tidak akan pernah lepas dari kehadiran gulma sebagaimana telah dipaparkan oleh Backer dalam Atlas of 220 weeds of sugarcane fields in Java pada tahun 1973. Hingga saat ini, informasi mengenai gulma-gulma di perkebunan tebu belum terhimpun secara utuh sedangkan kehadiran gulmagulma terkini semakin banyak dilaporkan. Penelitian ini bertujuan untuk inventarisasi jenis-jenis gulma perkebunan tebu di lima desa yang terletak di Kecamatan Asembagus dilakukan menggunakan metode jelajah. Sebanyak 97 jenis gulma kebun tebu yang termasuk ke dalam 27 suku ditemukan di Kecamatan Asembagus. Sepuluh jenis di antaranya belum dicatat oleh Backer sebagai gulma pada kebun tebu.
\end{abstract}

\begin{abstract}
Sugar cane agro-ecosystems will never be separated from the presence of weeds as described by Backer in his book Atlas of 220 weeds of sugarcane fields in Java on 1973. Until now, the information about weeds in sugar cane plantations has not been fully collected meanwhile the presence of newly recorded weeds is increasingly being reported. This research aimed to inventory of weeds of sugar cane plantations was carried out at five villages located in Asembagus Subdistrict, using the exploratory method. A total of 97 species of weeds belonging to 27 families were found in Asembagus Sub-district. As many as ten species have not been recorded before as sugar cane plantation weeds.
\end{abstract}

How to cite: Hariri, M.R \& Irsyam, A.S.D. (2019). Jenis-jenis Gulma Pada Kebun Tebu di Kecamatan Asembagus, Situbondo, Jawa Timur: Kelompok Eudikotiledon. Jurnal Riset Biologi dan Aplikasinya. 1 (2): 47-53.

E*Correspondence Author:

Jl. Ir. H. Djuanda No. 13, Bogor

e-ISSN 2655-9927

E-mail: muhammad.rifqi.hariri@lipi.go.id 


\section{PENDAHULUAN}

Tebu (Saccharum officinarum L.) mulai dibudidayakan secara intensif di pesisir utara Pulau Jawa sekitar tahun 1830 hingga 1870-an (Dell \& Olken, 2017). Pada era kolonial, pemerintah Hindia Belanda memusatkan perkebunan tebu di kawasan Jawa Timur dan sampai saat ini tebu masih menjadi salah satu komoditas yang penting di provinsi tersebut (Knight, 2014; Harlianingtyas et al., 2018). Berdasarkan catatan Badan Pusat Statistik (BPS) tahun 2017, Propinsi Jawa Timur memiliki lahan perkebunan tebu seluas 217.923 hektar (BPS, 2017). Salah satu kawasan di pesisir utara Jawa yang dijadikan lokasi penanaman tebu yaitu Kecamatan Asembagus di Kabupaten Situbondo (Harlianingtyas et al., 2018).

Suatu agroekosistem seperti perkebunan tebu, tidak akan lepas dari kehadiran gulma. Gulma dapat didefinisikan sebagai tumbuhan yang tumbuh di tempat yang tidak dikehendaki dan biasanya terdeteksi memiliki efek bagi lingkungan dan ekonomi (Richardson et al., 2000; Tjitrosoedirdjo et al., 2016a). Informasi mengenai jenis gulma di kebun tebu di Jawa telah terhimpun dalam buku Onkruidflora der Javasche suikerrietgronden yang ditulis oleh C.A. Backer dan terbit dari tahun 1928 hingga 1934. Seri buku ini terdiri atas satu jilid buku identifikasi dan 15 jilid atlas bergambar (Backer, 1973). Setelah atlas bergambar jilid kelimabelas terbit, sisa ilustrasi 220 jenis gulma belum sempat diterbitkan akibat krisis malaise dan perang dunia kedua. Selanjutnya, pada tahun 1973, ilustrasi-ilustrasi tersebut diterbitkan oleh van Steenis menjadi suatu kesatuan berjudul Atlas of 220 weeds of sugarcane fields in Java (Backer, 1973).

Sejak seri Onkruidflora der Javasche suikerrietgronden terbit, informasi terkini jenis gulma pada kebun tebu di Jawa belum tersedia. Sementara itu, saat ini jenis-jenis gulma yang belum tercatat oleh Backer sebelumnya dalam Flora of Java telah banyak dilaporkan, terutama dari kelompok Eudikotiledon atau tumbuhan berkeping biji dua. Beberapa di antaranya yaitu Praxelis clematidea (Griseb.) R.M.King \& H.Rob., Plectranthus monostachyus (P.Beauv.) B.J.Pollard, dan Solanum diphyllum L. (Hariri \& Irsyam, 2018; Irsyam \& Mountara, 2018; Tjitrosoedirdjo \& Wahyuni, 2018). Informasi jenis gulma kebun tebu di Kecamatan Asembagus juga belum terhimpun secara utuh. Oleh sebab itu, penelitian ini bertujuan untuk menginventarisasi jenis tumbuhan Eudikotiledon yang tumbuh menggulma pada perkebunan tebu di Kecamatan Asembagus, Situbondo.

\section{BAHAN DAN METODE}

Penelitian ini dilakukan di lima desa yang terletak di Kecamatan Asembagus, yaitu Desa Asembagus, Awar-awar, Gudang, Trigonco, dan Wringin Anom pada bulan Juni 2019. Pengamatan lapangan dilakukan menggunakan metode jelajah mengikuti Rugayah et al. (2004), yaitu dengan menjelajahi setiap sudut lokasi penelitian. Spesimen yang diambil berupa individu atau ranting yang lengkap dengan bagian vegetatif dan generatif. Data lapangan yang dicatat berupa nama kolektor, nomor koleksi, lokasi, tanggal, dan ciri-ciri morfologi yang dapat hilang selama proses pengawetan. Sampel selanjutnya diproses dan diamati lebih lanjut di Herbarium Bandungense (FIPIA), Sekolah Ilmu dan Teknologi Hayati (SITH), ITB.

Identifikasi dilakukan berdasarkan ciri morfologi pada spesimen, terutama bagian bunga atau buah. Spesimen dari lapangan selanjutnya diidentifikasi menggunakan 75 Important Invasive Plant Species in Indonesia (Tjitrosoedirdjo et al., 2016b), Atlas of 220 weeds of sugarcane fields in Java (Backer, 1973), Flora of Java vol 1 \& 2 (Backer \& Bakhuizen van den Brink, 1963; Backer \& Bakhuizen van den Brink, 1965), Geïllustreerd handboek der Javaansche theeonkruiden en hunne betekenis voor de cultuur (Backer \& van Slooten, 1924), Onkruidflora der Javasche suikerrietgronden (Backer, 1934), dan Weeds of Rice in Indonesia (Soerjani et al., 1987).

\section{HASIL DAN PEMBAHASAN}

Berdasarkan hasil pengamatan di perkebunan tebu lima desa di Kecamatan Asembagus, tumbuhan Eudikotiledon yang tumbuh menggulma terdiri dari 97 jenis dan termasuk ke dalam 27 suku. Suku dengan jumlah jenis terbanyak antara lain Fabaceae (16 jenis) dan Asteraceae (11 jenis). Jenis-jenis gulma pada kebun tebu di Kecamatan Asembagus disajikan dalam Tabel 1.

Suku Fabaceae atau polong-polongan merupakan kelompok tumbuhan dengan jumlah jenis terbanyak di lokasi penelitian, yaitu sebanyak 16 jenis. Berdasarkan bentuk perawakannya, keenambelas jenis tersebut terbagi menjadi kelompok terna dan perdu. Jenis yang termasuk terna yaitu, Aeschynomene americana, Centrosema pubescens, Clitoria ternatea, Dolichos lablab, Mimosa invisa, dan Pueraria phaseoloides. Sementara jenis berperawakan perdu yakni Clitoria laurifolia, Crotalaria pallida, C. retusa, Desmodium tortuosum, Indigofera galegoides, I. tinctoria. 
Tabel 1. Jenis-jenis gulma pada kebun tebu dari kelompok Eudikotiledon di Kecamatan Asembagus

\begin{tabular}{|c|c|c|c|c|c|c|c|}
\hline \multirow{2}{*}{ No } & \multirow{2}{*}{ Suku } & \multirow{2}{*}{ Jenis } & \multicolumn{5}{|c|}{ Lokasi } \\
\hline & & & As & Aw & $\mathbf{G}$ & $\mathbf{T}$ & $\mathbf{W}$ \\
\hline 1 & Acanthaceae & Asystasia gangetica (L.) T.Anderson & & & & $\sqrt{ }$ & \\
\hline 2 & & Barleria cristata L. & & & & $\sqrt{ }$ & \\
\hline 3 & & Ruellia tuberosa $\mathrm{L}$. & & $\sqrt{ }$ & $\sqrt{ }$ & $\sqrt{ }$ & $\sqrt{ }$ \\
\hline 4 & Amaranthaceae & Achyranthes bidentata Blume & & $\sqrt{ }$ & & $\sqrt{ }$ & $\sqrt{ }$ \\
\hline 5 & & Aerva lanata (L.) Juss. & $\sqrt{ }$ & $\sqrt{ }$ & & $\sqrt{ }$ & \\
\hline 6 & & Alternanthera brasiliana (L.) Kuntze & & & & & \\
\hline 7 & & Alternanthera philoxeroides (Mart.) Griseb. & & $\sqrt{ }$ & & & $\sqrt{ }$ \\
\hline 8 & & Alternanthera pungens Kunth & & $\sqrt{ }$ & & & \\
\hline 9 & & Alternanthera sessilis (L.) R.Br. ex DC. & & $\sqrt{ }$ & $\sqrt{ }$ & $\sqrt{ }$ & \\
\hline 10 & & Amaranthus spinosus L. & $\sqrt{ }$ & $\sqrt{ }$ & $\sqrt{ }$ & & $\sqrt{ }$ \\
\hline 11 & & Amaranthus viridis $\mathrm{L}$. & $\sqrt{ }$ & $\sqrt{ }$ & & & \\
\hline 12 & & Celosia argentea $\mathrm{L}$. & & $\sqrt{ }$ & & & \\
\hline 13 & & Gomphrena celosioides Mart. & $\sqrt{ }$ & & & & $\sqrt{ }$ \\
\hline 14 & Apiaceae & Centella asiatica $(\mathrm{L}$.$) Urb.$ & & & & $\sqrt{ }$ & \\
\hline 15 & Apocynaceae & Calotropis gigantea (L.) Dryand & & $\sqrt{ }$ & $\sqrt{ }$ & $\sqrt{ }$ & $\sqrt{ }$ \\
\hline 16 & & Catharanthus roseus (L.) G.Don & & & & & $\sqrt{ }$ \\
\hline 17 & Asteraceae & Ageratum conyzoides (L.) L. & & $\sqrt{ }$ & $\sqrt{ }$ & $\sqrt{ }$ & \\
\hline 18 & & Chromolaena odorata (L.) R.M.King \& H.Rob. & $\sqrt{ }$ & $\sqrt{ }$ & $\sqrt{ }$ & $\sqrt{ }$ & $\sqrt{ }$ \\
\hline 19 & & Cyanthillium cinereum (L.) H.Rob. & $\sqrt{ }$ & $\sqrt{ }$ & $\sqrt{ }$ & $\sqrt{ }$ & $\sqrt{ }$ \\
\hline 20 & & Cyanthillium patulum (Dryand. ex Dryand.) H.Rob. & & $\sqrt{ }$ & & & $\sqrt{ }$ \\
\hline 21 & & Emilia sonchifolia $($ L.) DC. ex DC. & & $\sqrt{ }$ & & $\sqrt{ }$ & \\
\hline 22 & & Mikania micrantha Kunth & $\sqrt{ }$ & $\sqrt{ }$ & $\sqrt{ }$ & $\sqrt{ }$ & $\sqrt{ }$ \\
\hline 23 & & Pluchea indica (L.) Less. & $\sqrt{ }$ & & & & \\
\hline 24 & & Sphagneticola trilobata (L.) Pruski & $\sqrt{ }$ & & $\sqrt{ }$ & & $\sqrt{ }$ \\
\hline 25 & & Synedrella nodiflora (L.) Gaertn. & $\sqrt{ }$ & $\sqrt{ }$ & $\sqrt{ }$ & $\sqrt{ }$ & $\sqrt{ }$ \\
\hline 26 & & Tridax procumbens (L.) L. & $\sqrt{ }$ & $\sqrt{ }$ & $\sqrt{ }$ & $\sqrt{ }$ & $\sqrt{ }$ \\
\hline 27 & & Wollastonia biflora (L.) DC. & & & $\sqrt{ }$ & $\sqrt{ }$ & $\sqrt{ }$ \\
\hline 28 & Cannabaceae & Trema orientalis (L.) Blume & & & & $\sqrt{ }$ & \\
\hline 29 & Cleomaceae & Cleome aspera J. König ex DC. & & & & $\sqrt{ }$ & $\sqrt{ }$ \\
\hline 30 & & Cleome gynandra $\mathrm{L}$. & $\sqrt{ }$ & $\sqrt{ }$ & $\sqrt{ }$ & $\sqrt{ }$ & $\sqrt{ }$ \\
\hline 31 & & Cleome viscosa $\mathrm{L}$. & & $\sqrt{ }$ & & & \\
\hline 33 & Convolvulaceae & Ipomoea fistulosa Mart. ex Choisy & $\sqrt{ }$ & & $\sqrt{ }$ & & $\sqrt{ }$ \\
\hline 34 & & Ipomoea hederifolia $\mathrm{L}$. & & $\sqrt{ }$ & & & \\
\hline 35 & & Ipomoea obscura (L.) Ker Gawl. & $\sqrt{ }$ & $\sqrt{ }$ & $\sqrt{ }$ & $\sqrt{ }$ & $\sqrt{ }$ \\
\hline 36 & & Ipomoea pes-tigridis $\mathrm{L}$ & & $\sqrt{ }$ & & & \\
\hline 37 & & Ipomoea triloba $\mathrm{L}$. & $\sqrt{ }$ & & $\sqrt{ }$ & $\sqrt{ }$ & \\
\hline 38 & & Merremia emarginata (Burm. f.) Hallier f. & & & & $\sqrt{ }$ & $\sqrt{ }$ \\
\hline 39 & Cucurbitaceae & Coccinia grandis (L.) Voigt & $\sqrt{ }$ & $\sqrt{ }$ & $\sqrt{ }$ & $\sqrt{ }$ & $\sqrt{ }$ \\
\hline 40 & & Momordica charantia $\mathrm{L}$. & & & & $\sqrt{ }$ & \\
\hline 41 & Euphorbiaceae & Acalypha indica $\mathrm{L}$. & $\sqrt{ }$ & $\sqrt{ }$ & $\sqrt{ }$ & $\sqrt{ }$ & $\sqrt{ }$ \\
\hline 42 & & Croton hirtus L'Hér. & & & & $\sqrt{ }$ & \\
\hline 43 & & Euphorbia heterophylla L. & $\sqrt{ }$ & & $\sqrt{ }$ & $\sqrt{ }$ & $\sqrt{ }$ \\
\hline 44 & & Euphorbia hirta $\mathrm{L}$ & $\sqrt{ }$ & $\sqrt{ }$ & $\sqrt{ }$ & $\sqrt{ }$ & $\sqrt{ }$ \\
\hline 45 & & Jatropha gossypiifolia L. & & & $\sqrt{ }$ & $\sqrt{ }$ & \\
\hline 46 & & Ricinus communis $\mathrm{L}$. & & $\sqrt{ }$ & $\sqrt{ }$ & $\sqrt{ }$ & \\
\hline 47 & Fabaceae & Aeschynomene americana $\mathrm{L}$. & & & $\sqrt{ }$ & $\sqrt{ }$ & \\
\hline 48 & & Centrosema pubescens Benth. & $\sqrt{ }$ & $\sqrt{ }$ & $\sqrt{ }$ & $\sqrt{ }$ & $\sqrt{ }$ \\
\hline 49 & & Clitoria laurifolia Poir. & & & & & \\
\hline 50 & & Clitoria ternatea $\mathrm{L}$. & & & & $\sqrt{ }$ & \\
\hline 51 & & Crotalaria pallida Aiton & & $\sqrt{ }$ & $\sqrt{ }$ & $\sqrt{ }$ & $\sqrt{ }$ \\
\hline 52 & & Crotalaria retusa $\mathrm{L}$. & & $\sqrt{ }$ & & $\sqrt{ }$ & \\
\hline 53 & & Desmodium tortuosum (Sw.) DC. & & & $\sqrt{ }$ & & \\
\hline 54 & & Dolichos lablab L. & $\sqrt{ }$ & & & & \\
\hline 55 & & Indigofera galegoides DC. & & $\sqrt{ }$ & & & \\
\hline 56 & & Indigofera tinctoria $L$. & & $\sqrt{ }$ & $\sqrt{ }$ & & $\sqrt{ }$ \\
\hline 57 & & Leucaena leucocephala (Lam.) de Wit & $\sqrt{ }$ & $\sqrt{ }$ & $\sqrt{ }$ & & $\sqrt{ }$ \\
\hline 58 & & Mimosa invisa Colla & $\sqrt{ }$ & $\sqrt{ }$ & $\sqrt{ }$ & $\sqrt{ }$ & \\
\hline 59 & & Mimosa pudica L. & $\sqrt{ }$ & $\sqrt{ }$ & $\sqrt{ }$ & $\sqrt{ }$ & $\sqrt{ }$ \\
\hline
\end{tabular}




\begin{tabular}{|c|c|c|c|c|c|c|c|}
\hline \multirow{2}{*}{ No } & \multirow{2}{*}{ Suku } & \multirow{2}{*}{ Jenis } & \multicolumn{5}{|c|}{ Lokasi } \\
\hline & & & As & Aw & $\mathbf{G}$ & $\mathbf{T}$ & W \\
\hline 60 & & Pueraria phaseoloides (Roxb.) Benth. & & & & $\sqrt{ }$ & \\
\hline 61 & & Senna occidentalis (L.) Link & & $\sqrt{ }$ & & & \\
\hline 62 & & Tephrosia purpurea (L.) Pers. & & $\sqrt{ }$ & $\sqrt{ }$ & $\sqrt{ }$ & \\
\hline 63 & Lamiaceae & Anisomeles indica (L.) Kuntze & & $\sqrt{ }$ & & & \\
\hline 64 & & Marsypianthes chamaedrys (Vahl) Kuntze & & $\sqrt{ }$ & $\sqrt{ }$ & $\sqrt{ }$ & \\
\hline 65 & & Ocimum americanum $\mathrm{L}$. & & $\sqrt{ }$ & & & $\sqrt{ }$ \\
\hline 66 & & Salvia misella Kunth & & $\sqrt{ }$ & & & $\sqrt{ }$ \\
\hline 67 & Linderniaceae & Lindernia crustacea (L.) F.Muell. & $\sqrt{ }$ & $\sqrt{ }$ & $\sqrt{ }$ & $\sqrt{ }$ & \\
\hline 68 & Malvaceae & Abutilon hirtum (Lam.) Sweet & & & $\sqrt{ }$ & $\sqrt{ }$ & $\sqrt{ }$ \\
\hline 69 & & Hibiscus surattensis $\mathrm{L}$. & & $\sqrt{ }$ & & $\sqrt{ }$ & \\
\hline 70 & & Malvastrum coromandelianum (L.) Garcke & & $\sqrt{ }$ & $\sqrt{ }$ & & $\sqrt{ }$ \\
\hline 71 & & Melochia corchorifolia L. & & $\sqrt{ }$ & & $\sqrt{ }$ & \\
\hline 72 & & Sida rhombifolia $\mathrm{L}$ & $\sqrt{ }$ & $\sqrt{ }$ & $\sqrt{ }$ & $\sqrt{ }$ & $\sqrt{ }$ \\
\hline 73 & & Thespesia lampas (Cav.) Dalzell \& A. Gibson & & & & $\sqrt{ }$ & \\
\hline 74 & & Triumfetta rhomboidea Jacq. & & $\sqrt{ }$ & & $\sqrt{ }$ & \\
\hline 75 & & Urena lobata $\mathrm{L}$ & & $\sqrt{ }$ & $\sqrt{ }$ & $\sqrt{ }$ & $\sqrt{ }$ \\
\hline 76 & & Waltheria indica $L$. & & $\sqrt{ }$ & & & \\
\hline 77 & Molluginaceae & Glinus oppositifolius (L.) Aug.DC. & & & $\sqrt{ }$ & & $\sqrt{ }$ \\
\hline 78 & Moraceae & Ficus callosa Willd. & & & & & $\sqrt{ }$ \\
\hline 79 & & Ficus septica Burm.f. & $\sqrt{ }$ & $\sqrt{ }$ & $\sqrt{ }$ & $\sqrt{ }$ & $\sqrt{ }$ \\
\hline 80 & Nyctaginaceae & Boerhavia erecta L. & $\sqrt{ }$ & $\sqrt{ }$ & $\sqrt{ }$ & $\sqrt{ }$ & $\sqrt{ }$ \\
\hline 81 & Passifloraceae & Passiflora foetida $\mathrm{L}$. & & & & $\sqrt{ }$ & \\
\hline 82 & Phyllanthaceae & Phyllanthus debilis Klein ex Willd. & $\sqrt{ }$ & $\sqrt{ }$ & $\sqrt{ }$ & $\sqrt{ }$ & $\sqrt{ }$ \\
\hline 83 & & Phyllanthus reticulatus Poir. & & & & $\sqrt{ }$ & \\
\hline 84 & & Phyllanthus urinaria $\mathrm{L}$. & $\sqrt{ }$ & $\sqrt{ }$ & $\sqrt{ }$ & $\sqrt{ }$ & $\sqrt{ }$ \\
\hline 85 & Plantaginaceae & Scoparia dulcis L. & $\sqrt{ }$ & $\sqrt{ }$ & $\sqrt{ }$ & $\sqrt{ }$ & $\sqrt{ }$ \\
\hline 86 & Plumbaginaceae & Plumbago zeylanica $\mathrm{L}$. & & $\sqrt{ }$ & & & \\
\hline 87 & Rubiaceae & Oldenlandia corymbosa $\mathrm{L}$. & & & & $\sqrt{ }$ & \\
\hline 88 & & Richardia brasiliensis Gomes & & & & $\sqrt{ }$ & \\
\hline 89 & & Richardia scabra L. & $\sqrt{ }$ & $\sqrt{ }$ & $\sqrt{ }$ & & \\
\hline 90 & Sapindacaee & Cardiospermum halicacabum $\mathrm{L}$. & & & & $\sqrt{ }$ & \\
\hline 91 & Solanaceae & Datura metel L. & & $\sqrt{ }$ & & & \\
\hline 92 & & Solanum americanum Mill. & & & & $\sqrt{ }$ & $\sqrt{ }$ \\
\hline 93 & & Solanum diphyllum $\mathrm{L}$. & & & & & $\sqrt{ }$ \\
\hline 94 & & Solanum torvum $\mathrm{Sw}$. & & & & & $\sqrt{ }$ \\
\hline 95 & Talinaceae & Talinum fruticosum (L.) Juss. & & & $\sqrt{ }$ & & \\
\hline 96 & Vitaceae & Cayratia trifolia (L.) Domin & $\sqrt{ }$ & & & & $\sqrt{ }$ \\
\hline 97 & Zygophyllaceae & Tribulus terrestris $\mathrm{L}$. & $\sqrt{ }$ & $\sqrt{ }$ & $\sqrt{ }$ & $\sqrt{ }$ & $\sqrt{ }$ \\
\hline
\end{tabular}

Keterangan: As= Asembagus; $\mathrm{Aw}=$ Awar-awar; $\mathrm{G}=$ Gudang; $\mathrm{T}=$ Trigonco; $\mathrm{W}=$ Wringin Anom

Leucaena leucocephala, Mimosa pudica, Senna occidentalis, dan Tephrosia purpurea. Penemuan ini didukung oleh penelitian terdahulu bahwa Jawa Timur merupakan pusat keanekaragaman tumbuhan polong yang berperawakan terna dan perdu di kawasan Malesia Barat (Raes et al., 2013). Selain itu, lokasi pengamatan merupakan kawasan perkebunan tebu yang terbuka. Raes et al. (2013) juga menyatakan bahwa daerah yang telah mengalami deforestasi dan alih guna lahan merupakan habitat yang ideal untuk tumbuhan terna dan perdu dari kelompok polong-polongan.

Suku dengan jumlah jenis terbanyak selanjutnya yaitu suku Asteraceae yang terdiri atas 11 jenis. Sebagian jenis Asteraceae kebun tebu merupakan tumbuhan introduksi dari kawasan
Afrika (Emilia sonchifolia, Synedrella nodiflora), Amerika Tropis (Ageratum conyzoides, Chromolaena odorata, Mikania micrantha, Sphagneticola trilobata), dan Meksiko (Tridax procumbens) (Soerjani et al., 1987; Tjitrosoedirdjo, 2002; Tjitrosoedirdjo et al., 2016b). Penelitian terdahulu menunjukkan bahwa banyak jenis Asteraceae yang telah diintroduksi ke Pulau Sumatera dan Jawa, kemudian ternaturasisasi di habitat alami (Soerjani et al., 1987; Tjitrosoedirdjo, 2002). Beberapa jenis yang ditemukan dari Kecamatan Asembagus juga telah ditetapkan menjadi tumbuhan asing invasif yang penting di Indonesia, yaitu C. odorata, M. micrantha, S. trilobata, dan Wollastonia biflora (Tjitrosoedirdjo et al., 2016b). 

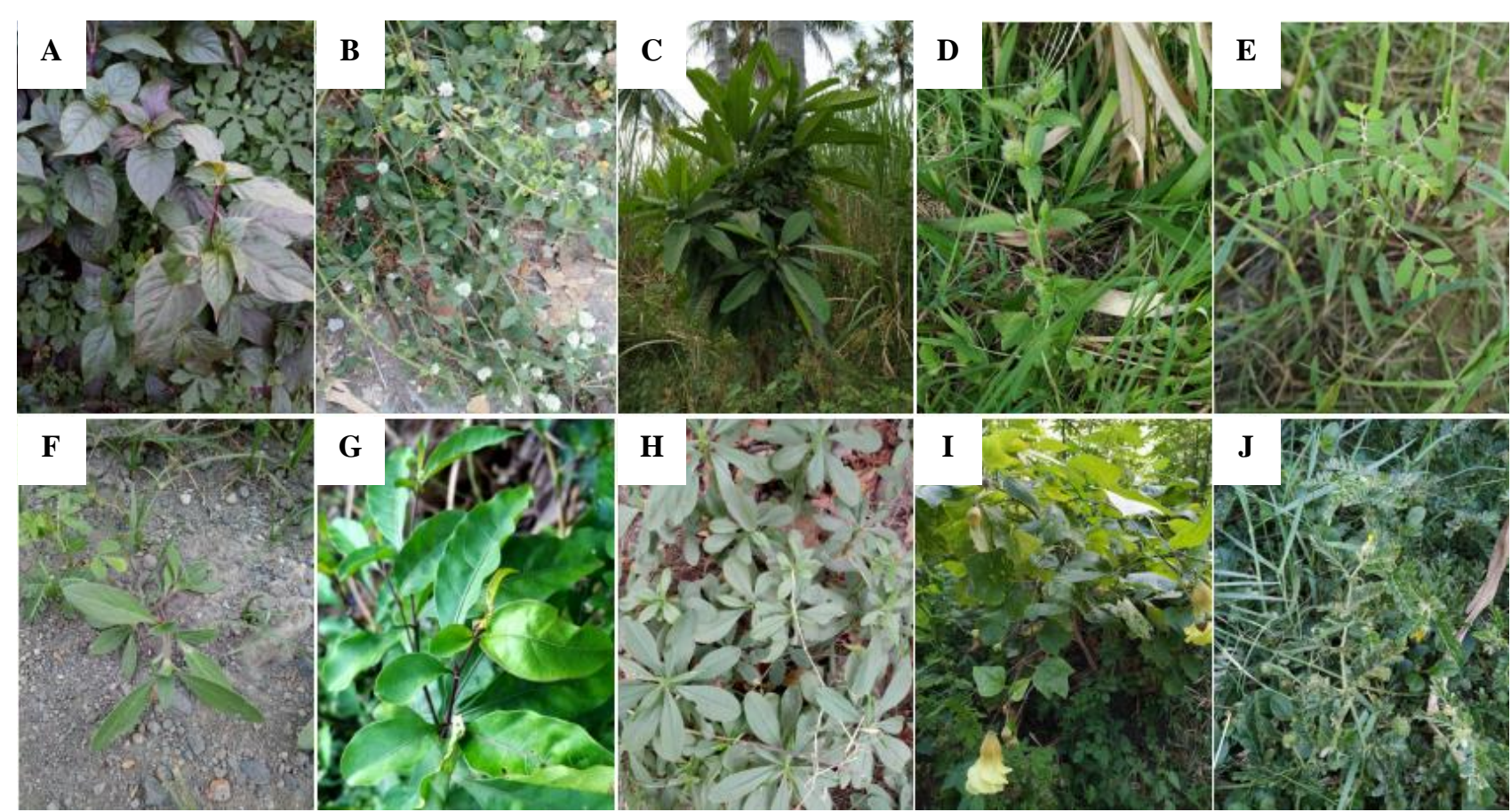

Gambar 1. Gulma perkebunan tebu rekaman baru dari Kecamatan Asembagus. $\mathrm{A}=A$. brasiliana, $\mathrm{B}=G$. celosioides, $\mathrm{C}=F$. callosa, $\mathrm{D}=M$. chamaedrys, $\mathrm{E}=P$. debilis, $\mathrm{F}=R$. scabra, $\mathrm{G}=S$. diphyllum, $\mathrm{H}=T$. fruticosum, $\mathrm{I}=$ Th. lampas, dan $\mathrm{J}=T r$. Terrestri.

Jenis tumbuhan dari suku Asteraceae mampu menghasilkan biji dalam jumlah yang besar, karena memiliki perbungaan majemuk berupa bonggol yang terdiri atas banyak bunga. Tjitrosoedirdjo et al. (2016a) menyatakan bahwa jumlah biji yang besar dapat memberikan kesempatan bagi suatu jenis asing untuk menghasilkan banyak keturunan, sehingga dapat membentuk populasi yang mapan pada lokasi yang belum terkolonisasi. Selain itu, pemencaran biji juga terjadi secara efektif karena adanya struktur pappus yang berasal dari modifikasi daun kelopak (Pyšek, 1997). Marga-marga seperti Ageratum, Chromolaena, Cyanthilium, Emilia, Mikania, Pluchea, dan Tridax memiliki pappus berupa bulu kejur yang akan membantu pemencaran biji secara anemokori. Sementara struktur pappus pada Synedrella berbentuk seperti duri sehingga memfasilitasi terjadinya pemencaran biji melalui mekanisme mamokori. Pemencaran biji yang efektif akan membantu gulma Asteraceae untuk menyebar secara luas ke tempat lain. Beberapa jenis seperti Mikania dan Sphagneticola juga dapat melakukan perkembangbiakan secara vegetatif melalui fragmentasi sehingga mudah tumbuh (Soerjani et al., 1987; Thaman, 1999). Faktor-faktor tersebut diduga menyebabkan banyak jenis Asteraceae yang berhasil tumbuh menggulma di daerah sebaran baru.
Sebanyak 87 jenis gulma pada kebun tebu yang diamati dari Kecamatan Asembagus telah terdaftar dalam Onkruidflora der Javasche suikerrietgronden (Backer, 1934). Namun, 10 jenis sisanya belum pernah dilaporkan sebelumnya sebagai gulma kebun tebu, yaitu Alternanthera brasiliana, Gomphrena celosioides, Ficus callosa, Marsypianthes chamaedrys, Phyllanthus debilis, Richardia scabra, Solanum diphyllum, Talinum fruticosum, Thespesia lampas, dan Tribulus terrestris (Gambar 1). Dengan demikian, penemuan ini memberikan informasi baru mengenai keanekaragaman jenis gulma pada kebun tebu di Jawa

Ficus callosa, P. debilis, dan S. diphyllum diduga belum tumbuh meliar di Jawa saat Backer menyusun daftar jenis gulma tebu, karena ketiga jenis tersebut juga tidak terekam dalam Flora of Java (Backer \& Bakhuizen van den Brink, 1963; Backer \& Bakhuizen van den Brink, 1965). Ficus callosa merupakan jenis yang berasal dari Asia Selatan, tersebar mulai dari Sri Lanka, India, Myanmar, Indochina, Thailand, hingga Kepulauan Andaman. Keberadaannya di Jawa baru terdaftar pada tahun 2005 dalam Flora Malesiana (Berg \& Corner, 2005). Phyllanthus debilis merupakan jenis yang berasal dari India dan Sri Lanka dan pertama kali dilaporkan sebagai gulma di Jawa pada tahun 1987 (Soerjani et al., 1987; Chantaranothai, 2005). Jenis tersebut sebelumnya tercatat sebagai gulma 
padi, namun pada penelitian ini $P$. debilis tumbuh sebagai gulma di kebun tebu. Sementara itu, $S$. diphyllum berasal dari Amerika Tengah dan telah ternaturalisasi di habitat alami karena lolos dari kultivasi. Keberadaan populasi $S$. diphyllum yang ternaturalisasi di Pulau Jawa baru dilaporkan pada tahun 2018 (Hariri \& Irsyam, 2018).

Jenis gulma seperti Catharanthus roseus, Datura metel, Leucaena leucocephala, Ocimum americanum, dan Talinum fruticosum, diduga berasal dari tanaman yang sebelumnya sengaja ditanam oleh warga sekitar. Leucaena leucocephala ditanam sebagai penyubur tanah dan pembatas kebun. Sementara jenis yang ditanam untuk keperluan obat tradisional yakni D. metel dan T. fruticosum. Ocimum americanum dan D. lablab dibudidayakan sebagai tanaman sayur, sedangkan $C$. roseus ditanam sebagai tanaman hias. Semua jenis tersebut menghasilkan biji dalam jumlah yang besar dan berukuran kecil sehingga sulit untuk dikontrol. Akibatnya, jenis-jenis ini lolos dari kultivasi dan tumbuh sebagai gulma di kawasan perkebunan tebu.

\section{SIMPULAN}

Tumbuhan gulma dari kelompok Eudikotiledon yang tumbuh di kebun tebu di Kecamatan Asembagus terdiri atas 97 jenis dan tercakup ke dalam 27 suku. Suku dengan jumlah jenis yang tinggi yaitu Fabaceae dan Asteraceae. Sebanyak 10 jenis gulma yang ditemukan dari lokasi pengamatan belum tercatat sebelumnya pada buku Onkruidflora der Javasche suikerrietgronden. Beberapa jenis tanaman budi daya seperti $C$. roseus, D. lablab, D. metel, L. leucocephala, $O$. americanum, dan $T$. fruticosum, telah ditemukan tumbuh menggulma di area perkebunan tebu.

\section{UCAPAN TERIMA KASIH}

Ucapan terima kasih penulis tujukan kepada petani tebu di Kecamatan Asembagus yang telah memberikan izin untuk pengamatan gulma selama penelitian ini berlangsung. Penulis juga mengucapkan terima kasih kepada Indah Wahyuni, S.Si, M,Si. yang telah membantu menyediakan referensi dari Perpustakan SEAMEO BIOTROP, Tajur, Bogor.

\section{DAFTAR PUSTAKA}

Backer, C.A. \& van Slooten, D.F. (1924). Geïllustreerd handboek der Javaansche theeonkruiden en hunne betekenis voor de cultuur. Batavia: Ruygok.

Backer, C.A. (1934). Onkruidflora der Javasche Suikerrietgronden. Soerabaia: H. van Ingen.
Backer, C.A. \& Bakhuizen van den Brink, R.C. (1963). Flora of Java. Vol. 1. Groningen: N.V.P. Noordhoff.

Backer, C.A. \& Bakhuizen van den Brink, R.C. (1965). Flora of Java. Vol. 2. Groningen: N.V.P. Noordhoff.

Backer, C.A. (1973). Atlas of 220 Weeds of Sugarcane Fields in Java. Deventer: The Ysel Press.

Berg, C.C. \& Corner, E.J.H. (2005). Moraceae: Ficeae. Flora Malesiana, Ser. I. 17(2), 1-70. Dikases dari https://borneoficus.info/wpcontent/uploads/2018/06/Berg-Corner2005-Flora-Malesiana-Moraceae-Ficus-.pdf.

BPS. (2017). Statistik Tebu Indonesia. http://www.bps.go.id/publication. Diakses tanggal 1 Juni 2019.

Chantaranothai, P. (2005). Taxonomic Notes on the genus Phyllanthus (Euphorbiaceae) in Thailand. Thai Forest Bulletin (Botany). 33, 1620. Diakses dari: https://www.tcithaijo.org/index.php/ThaiForestBulletin/arti cle/view/24223.

Dell, M. \& Olken, B.A. (2017). The Development Effects of the Extractive Colonial Economy: The Dutch Cultivation System in Java. The National Bureau of Economic Research Working Paper Series, 1-49. (DOI): 10.3386/w24009.

Hariri, M.R. \& Irsyam, A.S.D. (2018). Catatan Tentang Solanum diphyllum L. (Solanaceae) Ternaturalisasi di Pulau Jawa. Al-Kauniyah Jurnal Biologi, 11(1), 25-32. Doi: http://dx.doi.org/10.15408/kauniyah.v1 1i1.5 448.

Harlianingtyas, Hartati, D. \& Salim, A. (2018). Modeling of rainfall and fertilization factor of sugarcane productivity in Asembagus sugar factory Situbondo. IOP Conf. Ser.: Earth Environ. Sci., 207, 012013. doi:10.1088/17551315/207/1/012013.

Irsyam, A.S.D. \& Mountara, A. (2018). Plectranthus monostachyus (P Beauv.) B. J. Pollard (Lamiaceae) di Jawa. Floribunda, 6(1), 32-33. DOI: 10.32556/floribunda.v6i1.2018.223.

Knight, R. (2014). Sugar, Steam and Steel: The Industrial Project in Colonial Java, 1830-1885. Adelaide: The University of Adelaide.

Pysek, P. (1997). Compositae as invaders: Better than the others?. Preslia, 69(1), 9-22. Diakses dari

https://www.researchgate.net/publication/28 1663404 .

Raes, N., Saw, L.G., van Welzen, P.C. \& Yahara, T. (2013). Legume diversity as indicator for botanical diversity on Sundaland, South East Asia. South African Journal of Botany. 89: 265272.

DOI: https://doi.org/ 10.1016/j.sajb.2013.06.004.

Richardson, D.M., Pyšek, P., Rejmánek, M., Barbour, M.G., Panetta, F.D. \& West, C.J. 
(2000). Naturalization and invasion of alien plants: concepts and definitions. Diversity and Distributions, 6, 93-107.

Rugayah, Retnowati, A., Windadri, F.I. \& Hidayat, A. (2004). Pengumpulan Data Taksonomi. Dalam Rugayah, E.A. Widjaja \& Praptiwi (Eds). Pedoman Pengumpulan Data Keanekaragaman Flora (hlm. 5-42). Bogor: Puslit-LIPI. Doi: https://doi.org/10.1046/j.14724642.2000.00083.x

Soerjani, M., Kostermans, A.J.G.H. \& Tjitrosoepomo, G. (1987). Weeds of Rice in Indonesia. Jakarta: Balai Pustaka.

Thaman, R.R. (1999). Wedelia trilobata: Daisy invader of the Pacific Islands (IAS Technical Report No. 99/2). Suva, Fiji Islands: University of the South Pacific.

Tjitrosoedirdjo, S. (2002). Notes on The Asteraceae of Sumatera. Biotropia. 19: 65-84. Diakses dari http://journal.biotrop.org/index.php/biotropi a/article/view/230/199.

Tjitrosoedirdjo, S., Tjitrosoerdirdjo, S.S. \& Setyawati, T. (2016a). Tumbuhan Invasif dan pendekatan Pengelolaannya. Bogor: Seameo Biotrop.

Tjitrosoedirdjo, S.S., Mawardi, I. \& Tjitrosoerdirdjo, S. (2016b). 75 Important Invasive Plant Species in Indonesia. Bogor: Seameo Biotrop.

Tjitrosoerdirdjo, S.S. \& Wahyuni, I. (2018). Rekor baru keberadaan Praxelis clematidea (Asteraceae) di Indonesia. Dalam D. Kurniadie, D. Widayat \& U. Umiyati (Eds). Prosiding Seminar Nasional XX Himpunan Ilmu Gulma Indonesia: Resistensi Gulma Terhadap Herbisida dan Dampaknya terhadap Lingkungan dan Produk Pertanian (hlm. 212-217). Bogor: HIGI. 